NONLINEAR RESPONSE AND RESIDUAL STRENGTH OF DAMAGED

STIFFENED SHELLS SUBJECTED TO COMBINED LOADS

\author{
James H. Starnes, Jr., Vicki O. Britt and Cheryl A. Rose \\ NASA Langley Research Center \\ Hampton, VA 23681-0001 \\ and \\ Charles C. Rankin \\ Lockheed Palo Alto Research Laboratory \\ Palo Alto, CA 94304-1191
}

Presented at the AIAAASME/ASCE/AHS/ASC 37th Structures,
Structural Dynamics, and Materials Conference

AIAA Paper No. 96-1555

Salt Lake City, Utah

April 15-17, 1996 
, 


\title{
NONLINEAR RESPONSE AND RESIDUAL STRENGTH OF DAMAGED STIFFENED SHELLS SUBJECTED TO COMBINED LOADS
}

\author{
James H. Starnes, Jr.* , Vicki O. Britt ${ }^{\dagger}$ and Cheryl A. Rose ${ }^{\dagger}$ \\ NASA Langley Research Center \\ Hampton, VA 23681-0001 \\ and \\ Charles C. Rankin $\ddagger$ \\ Lockheed Palo Alto Research Laboratory \\ Palo Alto, CA 94304-1191
}

\begin{abstract}
$\underline{\text { Abstract }}$
The results of an analytical study of the nonlinear response of stiffened fuselage shells with long cracks are presented. The shells are modeled with a hierarchical modeling strategy and analyzed with a nonlinear shell analysis code that maintains the shell in a nonlinear equilibrium state while the crack is grown. The analysis accurately accounts for global and local structural response phenomena. Fuselage skins, frames, stringers and failsafe straps are included in the models. Results are presented for various combinations of internal pressure and mechanical bending, vertical shear and torsion loads, and the effects of crack orientation and location on the shell response are described. These results indicate that the nonlinear interaction between the in-plane stress resultants and the out-of-plane displacements near a crack can significantly affect the structural response of the shell, and the stress-intensity factors associated with the crack that are used to predict residual strength. The effects of representative combined loading conditions on the stress-intensity factors associated with a crack are presented. The effects of varying structural parameters on the stress-intensity factors associated with a crack, and on self-similar and non-sclf-similar crack-growth trajectorics are also presented.
\end{abstract}

\section{Introduclion}

Transport fuselage shell structures are designed to support combinations of internal pressure and mechanical flight loads which can cause the structure to have a geometrically nonlinear structural response. A

\footnotetext{
* Head, Structural Mechanics Branch. Fellow, AIAA.

$\dagger$ Acrospace Engineer, Structural Mechanics Branch. Member, AIAA.

$\ddagger$ Research Scientist.
}

transport fuselage structure is required to have adequate structural integrity so that the structure does not fail if cracks occur in service. The structural response of a stiffened fuselage shell structure with one or more cracks is influenced by the local stress and displacement gradients near the cracks and by the internal load distribution in the shell. Local displacements near a crack can be large compared to the fuselage skin thickness, and these displacements can couple with the internal stress resultants in the shell to amplify the magnitudes of the local stresses and displacements near the crack. This nonlinear response must be understood and accurately predicted in order to determine the structural integrity and residual strength of a fuselage structure.

Recent studies (e.g., Refs. 1-5) have shown that the stiffness and internal load distributions in a stiffened fuselage shell will change as a long crack grows in the shell. These changes affect the local stress and displacement gradients near the crack in a manner that may contribute to additional crack growth in the shell and, as a result, affect its structural integrity and residual strength. These studies show that the structural response and structural integrity of a stiffened fuselage shell with a crack can be studied analytically by the use of a nonlinear structural analysis procedure that models crack growth in the shell. The use of a nonlinear analysis procedure provides results that more accurately represent the local and global responses of a thin stiffened shell with a crack than the results from a more conventional linear analysis procedure for all loading conditions. Typical nonlinear analysis results presented in Ref. 5 indicate that different combinations of applied loads can cause different responses for a stiffened shell with a long crack. The magnitudes of the stressintensity factors associated with a long crack in a stiffened fuselage shell are affected significantly by different combinations of internal pressure and bending loads. The results in Ref. 5 indicate that the magnitude of the crack-opening stress-intensity factor for a shell subjected to internal pressure and an axial tension load

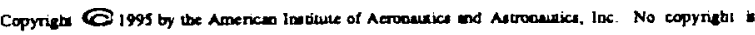

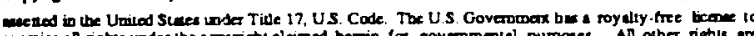

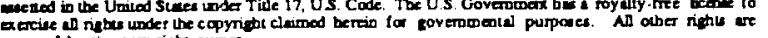


is less than the magnitude of the corresponding stressintensity factor for internal pressure only. The results also indicate that the magnitude of the crack-opening stress-intensity factor for a shell subjected to internal pressure and an axial compression load is greater than the magnitude of the corresponding stress-intensity factor for internal pressure only. The magnitude of this stress-intensity factor for an axial compression load and internal pressure is greater than the corresponding magnitudes of the other two loading conditions because the nonlinear coupling between the axial compression stresses and the out-of-plane displacements near the crack amplifies the magnitudes of the local stresses and displacements.

The present paper describes the results of an analytical study of the nonlinear response of a typical stiffened fuselage shell structure with long cracks and subjected to combinations of internal pressure and mechanical loads. Both longitudinal and circumferential cracks are considered in the study. The nonlinear analysis procedure and the modeling approach used in the study are described in the paper. Analytical results are presented for various combinations of internal pressure and mechanical bending, vertical shear and torsion loads. The results illustrate the influence of different loading conditions on the local stress and displacement gradients near a crack, on the magnitudes of the stress-intensity factors associated with the crack, and on crack-growth trajectories. The effects of varying structural parameters, such as failsafe-strap and stiffener thicknesses, and varying crack location on the results are described. The effects of different loading conditions on both self-similar and non-self-similar crack-growth results are also presented.

\section{Nonlinear Analysis Procedure and Hierarchical Modeling Strategy}

A nonlinear shell analysis procedure combined with a hierarchical modeling strategy is used in the present study to analyze the nonlinear response of a typical stiffened fuselage shell with long skin cracks. The loads applicd to the shell include various combinations of intemal pressure and mechanical flight loads. The analysis procedure models crack growth in a shell while the shell is in a nonlinear equilibrium state, and determínes local stress and displacement gradients and other local response phenomena, in critical areas of a fuselage where cracks may be growing. The analysis procedure accurately models frame and stringer crosssectional distortion and rolling, and predicts the nonlinear interactions that occur between individual structural elements and larger subcomponents as a result of these deformations. The details of the analysis procedure and modeling strategy are discussed subsequently.

\section{Nonlinear Analysis Procedure}

The STAGS (STructural Analysis of General Shells) nonlinear finite element analysis code ${ }^{6}$ is used in the present study to conduct nonlinear structural analyses of stiffened shells with long cracks. STAGS is a finite element code for analyzing general shells and includes the effects of geometric and material nonlinearities in the analysis. STAGS is capable of conducting strength, stability and collapse analyses for general shell structures. The code uses both the modified and full Newton methods for its nonlinear solution algorithms, and accounts for large rotations in a shell by using a co-rotational algorithm at the element level. STAGS has static and transient analysis capabilities that can be used to predict local instabilities and modal interactions that occur due to destabilizing mechanical loads, such as an applied compression or shear load. The Riks pseudo arc-length path following method $^{7.8}$ is used to continue a solution past the limit points of a nonlinear response. A boundary constraint function, based on a least-squares analysis, is used to apply equivalent beam loads to the boundary of a thinshell finite element model without artificially distorting the shcll wall. By using this least-squares constraint function, flight loads can be extracted from a global aircraft model and then applied as edge loads on the boundaries of a refined finite element model of a fuselage shell section.

STAGS can perform crack-propagation and residualstrength analyses, and can represent the effects of crack growth on nonlinear shell response. A node-release method and a load-relaxation technique are used to extend the length of a crack while the shell is in a nonlinear equilibrium state. ${ }^{3}$ The forces necessary to hold the nodes together along the path of new crack growth are calculated with this method. These forces are relaxed as the crack is extended, and a new equilibrium state is calculated which corresponds to the longer crack. The changes in the stiffness matrix and the internal load distribution that occur during crack growth are accounted for in the analysis, and the nonlinear coupling between internal forces and in-plane and out-of-plane displacement gradients that occurs in a shell are properly represented. Cracks in built-up structures and structural elements, such as frames, stringers and failsafe straps, can also be modeled by STAGS. Results from STAGS calculations include strain-energy-release rates and stress-intensity factors ${ }^{3.9}$ that can be used to calculate the residual strength of a damaged shell.

The FRANC3D (FRacture ANalysis Code for 3D surfaces) fracture analysis code ${ }^{10}$ has been interfaced with STAGS and is used to determine the finite element mesh distribution required to predict curved or non-self- 
similar crack-growth trajectories. Curved crack growth is simulated by using the adaptive mesh refinement capability of the solid modeling code FRANC3D. STAGS results are transmitted to FRANC3D which then computes fracture parameters that govern crack growth. After the crack has grown, FRANC3D creates a new finite element mesh in the area of the crack for each increment of crack growth. The STAGS results from the previous finite element mesh are mapped onto the new finite element mesh with a transformation subroutine that is compatible with STAGS. The nonlinear STAGS analysis can then be continued with the new finite element mesh results from FRANC3D

\section{Hierarchical Modeling Strategy}

A hierarchical stiffened-shell modeling strategy is used in the present study for the analysis of stiffened fuselage shell sections. The hierarchical modeling strategy begins with a global nonlinear analysis of a large stiffened fuselage shell section that is subjected to combined internal pressure and mechanical loads. The mechanical loads are applied to the ends of the fuselage section and can include any combination of axial, vertical shear, torsion, and bending loads. The global model includes structural details such as frames, stringers, failsafe straps, shear clips, floor beams and stanchions. The skin of the global model is modeled with shell elements. The frames, which may have nonsymmetric cross sections, are modeled with a combination of shell and beam elements in order to represent accurately the cross-sectional bending of the frame. The stringers, shear clips, failsafe straps, floor beams and stanchions are modeled with beam elements. Damage is included in the model in the form of longitudinal or circumferential cracks and may also include broken frames, stringers and failsafe straps. Displacements are obtained from the analysis of the global model and are then used as boundary conditions for the next level of modeling detail used in the hierarchical modeling strategy.

The second level of modeling detail used in the hierarchical modeling strategy represents a stiffenedpanel structural model. This stiffened-panel model has a higher degree of mesh refinement and structural detail than the global model previously described in order to represent the structural response more accurately. Frames, stringers and shear clips are modeled as branched shells in the stiffened-panel model, and the failsafe straps are modeled using shell elements. Distortion of structural elements, such as frames and stringers, is accurately accounted for at this modeling level, and a mesh with sufficient refinement around the crack tip is used to calculatc crack-growth parameters. boundary conditions for a third level of modeling detail that includes smaller, more-detailed local-panel models. These detailed local models include a damaged area of the shell, and may also include structural details such as lap joints and fasteners which are modeled using nonlinear spring elements in STAGS. A detailed fracture mechanics analysis is performed at this modeling level to determine crack-growth characteristics. As a crack grows, changes occur in the stress and displacement fields of the local models. These changes are accounted for in the more global models by reanalyzing these models with the new crack configurations. This procedure is repeated for all levels of modeling detail at each stage of crack growth.

\section{Fuselage Shell Model}

The fuselage shell analyzed in this study is a typical generic narrow-body transport fuselage shell made of aluminum. The shell has a 74 -inch radius, an 0.036 -inch-thick skin and is 160 inches long. There are nine frames that are spaced 20 inches apart and fifty stringers that are spaced 9.3 inches apart. Failsafe straps are located beneath each stringer and frame, and there are additional circumferential failsafe straps located midway between frames. Frames, stringers, failsafe straps, floor beams and stanchions have nominal stiffness properties of typical narrow-body transport fuselage structures. The failsafe straps are nominally 0.036 inches thick and the stringers have a constant thickness that is nominally 0.028 inches thick throughout the stringer cross section, unless otherwise noted.

The loads considered in the present study include internal pressure, bending, vertical shear, and torsion loads. A maximum value of 8 psi is used for the magnitude of the internal pressure for all of the results. This pressure represents the nominal operating pressure in the passenger cabin of a typical subsonic transport. Tensile axial stress resultants are applied to the model to represent the loads from the pressure bulkheads. The magnitudes of the bending and vertical shear loads used in this study are the maximum values of these applied loads that can be supported without buckling the fuselage skin. The value of the applied bending load is a moment of $6,325,000$ in.-lbs, the value of the applied vertical shear load is a force of $50,000 \mathrm{lbs}$, and the value of the applied torsion load is a torsional moment of $6,325,000 \mathrm{in}$.-lbs, unless otherwise noted. The bending loads are applied to the model so that the fuselage crown is loaded in axial compression. Axial compression loads have been found ${ }^{5}$ to cause the stress-intensity factors associated with a longitudinal crack to have higher magnitudes than those for axial tension loads.

Displacements obtained from the stiffened-panel model, or sccond level of modeling detail, are used as 


\section{Results and Discussion}

The results of an analytical study of the nonlinear response of a stiffened fuselage shell with long cracks are presented in this section. Results have been generated for seven loading conditions with various combinations of intemal pressure, vertical shear, torsion, and bending loads. The seven loading conditions include: internal pressure plus a bending load; internal pressure plus a vertical shear load; internal pressure plus a torsion load; internal pressure plus bending and torsion loads; internal pressure plus bending and vertical shear loads; internal pressure plus vertical shear and torsion loads; and internal pressure plus bending, vertical shear and torsion loads. Results have been generated for two crack configurations. One crack configuration is a longitudinal crack located in the crown of the fusclage and is centered over a broken circumferential failsafe strap that is located midway between two frames. The other crack configuration is a circumferential crack located in the crown of the fuselage. This crack is centered over a broken stringer at the top of the fuselage and is located midway between a frame and a midbay circumferential failsafe strap. Typical results are presented to illustrate the effects of crack location and orientation on shell response for the applied loading conditions studied. Additional results are presented in Ref. 5 that illustrate the effects of other combinations of internal pressure, bending and vertical shear loads on the response of stiffened fuselage shells with longitudinal cracks in fuselage crown and side panels.

\section{Stiffened Shell with a Longitudinal Crack}

Representative results for the global stiffened shell model with a 10.0-inch-long longitudinal crack in a fuselage crown panel are shown in figure 1 for combined internal pressure, torsion and bending loads; and in figure 2 for combined internal pressure, vertical shear, torsion and bending loads. The results for the other five loading conditions are similar to these representative results. Contour plots of the axial, hoop and shear stress resultants in the skin of the shell are shown on the corresponding deformed shapes in the figures. Side views of the fuselage shell are shown in the figures. The prominent local deformation pattern at the top of each figure indicates the deformations in the shell associated with the crack. The smaller local deformation patterns in the skin, that are visible along the top and bottom of each figure, indicate the bending gradients in the skin at each frame location that are associated with the internal pressure. Comparing the results in the figures indicates the influence of the vertical shear and torsion loads on the stress resultant distributions in the skin of the fuselage shell, and how the combined applied loads affect the internal load distributions in the shell.
The results shown in figure la indicate the axial stress resultant distribution in the shell for internal pressure, bending and torsion loads. The darker shades in the figure represent higher values of tensile axial stress resultants, and the lighter shades represent higher values of compressive axial stress resultants. The distribution of these axial stress resultants varies around the circumference of the shell but does not vary along the length of the shell, which is consistent with an applied bending load. The torsion load has a small, but noticeable effect on the axial stress resultant distribution. The results shown in figure $1 \mathrm{~b}$ indicate the hoop stress resultant distribution in the shell for this loading condition. The darker shades in the figure represent higher values of tensile hoop stress resultants in the skin between the frames, and the lighter shades represent lower values of tensile hoop stress resultants in the skin at the frames. The lower values of tensile hoop stress resultants in the skin at the frames indicate that the frames support part of the hoop tensile loads caused by the internal pressure. The lighter shades in the crack region indicate that the hoop stress resultant approaches a value of zero at the edges of the crack. The results shown in figure $1 \mathrm{c}$ indicate the shear stress resultant distribution in the shell for this loading condition. The lighter shades in the figure represent a nearly uniform shear stress resultant distribution in the skin which is consistent with an applied torsion load. The darker shades in the crack region indicate that there is a local gradient in the shear stress resultant near the crack. The results indicate that the internal pressure and bending loads do not affect the shear stress resultant distribution in the shell for this loading condition, crack location and crack orientation.

The results shown in figure $2 \mathrm{a}$ indicate the axial stress resultant distribution in the shell for internal pressure, bending, vertical shear and torsion loads. The darker shades in the figure represent higher values of tensile axial stress resultants, and the lighter shades represent higher values of compressive axial stress resultants. The distribution of these axial stress resultants varies around the circumference and along the length of the shell, which is consistent with the applied bending and vertical shear loads. The hoop stress resultant distribution for this loading condition is similar to the results shown in figure $1 b$. The results shown in figure $2 b$ indicate the shear stress resultant distribution in the shell for this loading condition. The lighter shades in the figure represent negatives value of the shear stress resultant, and the darker shades represent positive values of the shear stress resultant. A positive value of a shear stress resultant represents a shear stress resultant that is consistent with the sense of the applied torsion load, and a negative value represents a shear stress resultant that is in the opposite direction. The results indicate that the shear stress resultant 
distribution is not uniform around the circumference of the shell, which is consistent with the combination of applied vertical shear and torsion loads. The darker shades in the crack region indicate that there is a gradient in the shear stress resultant near the crack. The results indicate that the internal pressure and bending loads do not affect the shear stress resultant distribution in the shell for this loading condition, crack location and crack orientation.

Results presented in Ref. 5 indicate that other combinations of loading conditions, crack locations and crack orientations can have different effects on the stress resultant distributions in a stiffened fuselage shell. The results from the present study and those presented in Ref. 5 can be used to provide insight into the effects of other crack configurations and loading conditions on the response of a stiffened fuselage shell with a long crack at various locations in the shell.

\section{Stiffened Panels with a Longitudinal Crack}

Displacements obtained from the analysis of the global stiffened-shell model with a crack are applied as boundary conditions to the second level of modeling detail, which represents a crown-panel section with five frames, five stringers, and six longitudinal and six circumferential skin bays. At this level of finite element mesh refinement, the stress and displacement gradients near the frames, the stringers, and the longitudinal crack are more accurately represented than for the larger, less-refined global stiffened shell model. The longitudinal crack length is grown from an initial length of 6.0 inches to 18.5 inches during the analysis using the load-relaxation technique in STAGS, while the stiffened panel is maintained in a nonlinear equilibrium state. The stress resultant distributions from the nonlinear analyses are shown on the corresponding deformed shapes in figures 3 and 4 for two representative loading conditions.

The results shown in figure $3 \mathrm{a}$ indicate the axial stress resultant distribution in the panel with an 18.5 . inch-long longitudinal crack and subjected to internal pressure, vertical shear and bending loads. The darker shades in the figure represent higher values of tensile axial stress resultants, and the lighter shades represent higher values of compressive axial stress resultants. The vertical shear and bending loads cause the axial stress resultants in the crown panel to be in compression except for the local region near the crack. These compressive axial stress resultants couple with the out-of-plane displacements near the crack and amplify the magnitudes of the stress resultants near the crack. This response causes the edges of the crack to spread apart, which opens the crack. The skin at the edge of the crack for this loading condition is in tension in the axial direction because of the outward bulging deformations in the local crack region that are caused by intemal pressure. The outward bulging deformations in the local crack region are the same on both sides of the crack for this loading condition, and the results shown in figure $3 \mathrm{~b}$ indicate the hoop stress resultant distribution in the panel. The darker shades in the figure represent higher values of tensile hoop stress resultants, and the lighter shades represent lower values of tensile hoop stress resultants. The lighter shades in the crack region indicate that the hoop stress resultant approaches a value of zero at the edge of the crack, and the darker shades at the crack tips indicate that there is a local gradient in the hoop stress resultant at the crack tips. The results shown in figure $3 \mathrm{c}$ indicate the shear stress resultant distribution in the panel for this loading condition. The lighter shades in the figure represent negative values of the shear stress resultants, and the darker shades represent positive values of the shear stress resultants. The results indicate that there is a local gradient in the shear stress resultant near the crack.

The results shown in figure $4 \mathrm{a}$ indicate the axial stress resultant distribution in the panel with an 18.5inch-long longitudinal crack and subjected to internal pressure and torsion loads. The darker shades in the figure represent higher values of tensile axial stress resultants, and the lighter shades represent higher values of compressive axial stress resultants. The axial stress resultants in the crown panel are mostly in tension except for the local region near the crack where there are some compressive axial stress resultants. The skin at the edge of the crack for this loading condition is in tension in the axial direction because of the outward bulging deformations in the local crack region that are caused by the internal pressure. The outward bulging deformations in the local crack region are not the same on both sides of the crack for this loading condition, and the edges of the crack are displaced axially or sheared relative to one another. The torsion load causes the edges of the crack to shear relative to one another, and the local displacements of the crack are not consistent with a simple crack-opening mode. The hoop stress resultant distribution for this loading condition is similar to the results shown in figure $1 \mathrm{~b}$, but is slightly nonsymmetric due to the torsion load as shown in figure $4 \mathrm{~b}$. The results indicate that the hoop stress resultant in the skin at the crack tip has a relatively high tensile value for this loading condition. The results shown in figure $4 \mathrm{c}$ indicate the shear stress resultant distribution in the panel for this loading condition. The lighter shades in the figure represent negative values of the shear stress resultant, and the darker shades represent positive values of the shear stress resultant. The darker shades in the crack region indicate that there is a gradient in the shear stress resultant near the crack. 
The stress-intensity factors $K_{1}$ and $K_{I I}$, which correspond to a crack-opening mode and a crack-shearing mode, respectively, for the seven combined loading conditions considered in this study are shown in figures $5 \mathrm{a}$ and $5 \mathrm{~b}$, respectively, as a function of crack length. The legend in the figures identifies the loading conditions by combinations of the letters $P, M, S$ and $T$, which indicate the internal pressure, bending, vertical shear, and torsion loads, respectively. The solid lines represent results for internal pressure plus one mechanical load component, and the dashed lines represent results for internal pressure plus more that one mechanical load component. The loading conditions with the bending load $(M)$ and the vertical shear load (S) have higher values of $K_{1}$ than those with the torsion load $(\mathrm{T})$. The bending and vertical shear loads cause high values of compressive axial stress resultants in the crown panel which couple with the out-of-plane deformation due to crack bulging to open the crack faces and cause higher values of $K_{1}$. The loading conditions with the torsion load have high values of shear stress resultants in the crown panel and are not represented by a simple crack-opening response because the crack faces displace or shear relative to one another. The loading conditions with a torsion load have higher values of $K_{11}$ than those without a torsion load. The curves in figure 5 a representing the change in $K_{1}$ as the crack length increases are not linear. As the crack length increases, the loads in the skin are redistributed to the frames and failsafe straps, and the cross-sections of the stringers on either side of the crack distort enough to reduce the stiffnesses of the stiffener. Hoop stress resultant distributions near the crack are shown on the corresponding deformed surfaces in figure 6 for 6.0-, 12.0-, and 18.5-inch-long cracks. This load redistribution from the skin to the frames and the failsafe straps, and the stiffener stiffness decrease due to stiffener distortion, decreases the rate of increase in the value of $K_{1}$ as the crack length increases.

The values of the stress-intensity factors are used to determine the residual strength of the stiffened shell structure as the crack grows. An example of the residual strength results for an extreme case of a longitudinal crack in the skin and a broken frame is shown in figure 7. The gross residual strength in the figure is determined from the stresses in the skin and in the next intact frame. The far-field hoop stress in the skin is plotted as the solid curve in the figure as the crack length increases, and is determined from the pressure that would cause the stress-intensity factor at the crack tip to be equal to the critical value of the stress-intensity factor for each value of the crack length. The stress in the frame is plotted as the dashed curve in the figure as the crack length increases, and is determined from the results that correspond to the yield stress in the frame. In general, the results in the figure indicate that the residual strength of the skin and the frame decrease as the crack grows. The residual strength of the skin increases slightly as the crack approaches a failsafe strap because some of the skin load is redistributed to the failsafe strap. The residual strength of the frame decreases once the crack has grown past the failsafe strap because more of the skin load is redistributed to the frame, which causes the frame to yield at lower values of load. The crack in the skin will grow before the frame yields if the residual strength results for the skin are less than the results for the frame. The frame will yield before the skin crack grows when the residual strength results for the frame are less than the results for the skin. The structure has no residual strength when the two curves intersect indicating that the skin crack will grow at the same time the frame fails.

\section{Stiffened Panels with a Circumferential Crack}

Displacements obtained from the analysis of the global stiffened shell model with a crack are applied as boundary conditions to the second level of modeling detail, which represents a crown-panel section with five frames, five stringers, and six longitudinal and six circumferential skin bays. At this level of finite element mesh refinement, the stress and displacement gradients near the frames, the stringers, and the circumferential crack are more accurately represented than for the larger, less-refined global stiffened shell model. The circumferential crack length is grown from an initial length of 4.7 inches to 17.7 inches during the analysis using the load-relaxation technique in STAGS while the stiffened panel is maintained in a nonlinear equilibrium state. The stress resultant distributions from the nonlinear analyses are shown on the corresponding deformed shapes in figures 8 and 9 for two representative loading conditions.

The results shown in figure 8a indicate the axial stress resultant distribution in the panel with a 17.7inch-long circumferential crack and subjected to internal pressure and vertical shear loads. The darker shades in the figure represent higher values of tensile axial stress resultants, and the lighter shades represent higher values of compressive axial stress resultants. The vertical shear load causes the axial stress resultants in the crown panel to vary along the length of the panel, and the axial stress resultant near the crack can be either in tension or in compression depending on the crack location. For this crack location, the axial stress resultant is in compression near the crack and tends to close the crack. The outward bulging deformations in the local crack region are not the same on both sides of the crack for this loading condition. The displacements of the edges of the crack are symmetric in the circumferential direction, but are not symmetric in the axial direction because the frame and failsafe strap on either side of the crack have different stiffnesses. The 
results shown in figure $8 \mathrm{~b}$ indicate the hoop stress resultant distribution in the panel for this loading condition. The darker shades in the figure represent higher values of tensile hoop stress resultants, and the lighter shades represent lower values of tensile hoop stress resultants. The hoop stress resultant does not approach a value of zero at the edge of the crack for this loading condition and crack configuration, as it does for the longitudinal crack discussed previously. The skin at the edges of the crack is in tension in the hoop direction for this loading condition due to the outward bulging deformations in the local crack region that are caused by the internal pressure. The results shown in figure $8 \mathrm{c}$ indicate the shear stress resultant distribution in the panel for this loading condition. The lighter shades in the figure represent negative values of the shear stress resultants, and the darker shades represent positive values of the shear stress resultants. The results indicate that there is a small local gradient in the shear stress resultant near the crack.

The results shown in figure $9 \mathrm{a}$ indicate the axial stress resultant distribution in the panel with a 17.7. inch-long circumferential crack and subjected to internal pressure and torsion loads. The darker shades in the figure represent higher values of tensile axial stress resultants, and the lighter shades represent higher values of compressive axial stress resultants. The axial stress resultants in the crown panel are primarily in tension. The outward bulging deformations in the local crack region are not the same on both sides of the crack for this loading condition, and the edges of the crack are displaced circumferentially or sheared relative to one another and significantly distorted. The torsion load causes the edges of the crack to shear relative to one another, and the local displacements of the crack are not representative of a simple crack-opening mode. The hoop stress resultant distribution for this loading condition is shown in figure $9 \mathrm{~b}$ and is nonsymmetric due to the torsion load. The results indicate that the hoop stress resultant in the skin at the crack tips has a relatively high tensile value for this loading condition. The results shown in figure $9 \mathrm{c}$ indicate the shear stress resultant distribution in the panel for this loading condition. The lighter shades in the figure represent negative values of the shear stress resultant, and the darker shades represent positive values of the shear stress resultant. The darker shades in the crack region indicate that there is a gradient in the shear stress resultant near the crack.

The stress-intensity factors $K_{1}$ and $K_{\mathrm{n}}$, which correspond to a crack-opening mode and a crack-shearing mode, respectively, for the seven combined loading conditions considered in this study are shown in figures $10 \mathrm{a}$ and $10 \mathrm{~b}$, respectively, as a function of crack length. The legend in the figures identifies the loading conditions by combinations of the letters $P, M, S$ and
$T$, which indicate the internal pressure, bending, vertical shear, and torsion loads, respectively. The solid lines represent results for internal pressure plus one mechanical load component, and the dashed lines represent results for intemal pressure plus more that one mechanical load component. One half of the values of the moment and vertical shear loads are used in the analysis for the loading conditions with both the bending $(M)$ and vertical shear loads $(S)$ to prevent the panel from buckling locally at low values of the applied load. The results indicate that the loading condition with internal pressure and a torsion load has the highest value of $\mathrm{K}_{\mathrm{l}}$, and all loading conditions with a torsion load have high values of $K_{\text {II }}$. For a torsion load only, there is no axial compression to close the crack which would cause a higher value of $K_{1}$. The torsion load causes one crack face to deform more than the other, which causes a higher value of $\mathrm{K}_{\mathrm{n}}$. The bending and vertical shear loads cause the crack to close, which reduces the value of $\mathrm{K}_{\mathrm{l}}$. The curves representing the change in $\mathrm{K}_{1}$ and $\mathrm{K}_{\mathrm{I}}$ as a function of crack length in figures $10 \mathrm{a}$ and $10 \mathrm{~b}$ are not linear as the crack length increases because of the intemal load redistribution that occurs. The redistribution of internal loads changes the stress magnitudes in the skin, and, as a result, changes the magnitudes of the stress-intensity factors.

The effects of varying stiffener thicknesses on the stress-intensity factors $K_{1}$ and $K_{I I}$ for a panel with a circumferential crack and subjected to intemal pressure and a torsion load are shown in figures $11 \mathrm{a}$ and $11 \mathrm{~b}$, respectively. The results in the figures are for stiffener thicknesses of $0.028,0.036$ and 0.040 inches. The length of the crack varies from 4.7 to 17.7 inches. The stress resultants and deformed shape for the panel with 0.036-inch-thick stiffeners are shown in figure 9 and are representative of the results for the other stiffener thicknesses. The results in figure $11 \mathrm{a}$ indicate that $\mathrm{K}_{\mathrm{I}}$ increases as the stiffener thickness decreases for increasing crack length, which suggests that the skin has higher axial stress resultants if the stringer is thinner. The results in figure $11 \mathrm{~b}$ indicate that $K_{n}$ decreases as the stiffener thickness increases for increasing crack length, which suggests that the thicker stiffeners restrain the shear deformations near the crack enough to reduce the shear stress resultants in the skin. The values of $K_{1}$ and $K_{1 I}$ both decrease as the crack length increases beyond approximately 15.0 inches because the crack tips are approaching the stringers on either side of the broken stringer and the load in the skin is redistributed to the intact stringers.

\section{Crack-Growth Trajectories}

The effects of loading condition and crack location on crack growth trajectories are studied using a detailed two-bay by three-bay local-panel model that is centered around the crack. Displacements obtained from the six- 
bay by six-bay stiffened panel model are applied as boundary conditions for the two-bay by three-bay localpanel model which has a higher level of mesh refinement in order to represent the structural response of the crack region more accurately. Nonlinear solutions from STAGS for the local-panel models are mapped onto a FRANC3D model to determine the changes in the crack-growth trajectory. The local finite element mesh near the crack is refined by FRANC3D and the direction for the next increment of crack growth is determined. The refined mesh from FRANC3D is then mapped onto the STAGS model for additional nonlinear analyses.

Crack-growth trajectories are shown in figure 12 for three representative longitudinal crack locations and loading conditions. The initial crack length for these longitudinal crack configurations is 6.0 inches, and the crack is located either midway between two stringers or 1.2 inches from a stringer as shown in figures 12a and $12 \mathrm{~b}$, respectively. The crack-growth trajectory for the crack located midway between two stringers in a panel subjected to internal pressure, bending and vertical shear loads is shown in figure $12 \mathrm{c}$ for a crack length of 16.0 inches. The crack-growth trajectory for this case is a self-similar crack-growth trajectory due to the symmetry of the loading condition and geometry. The deformed shape for this crack length is shown in figure 13. The crack-growth trajectory for the crack located 1.2 inches from a stringer in a panel subjected to internal pressure, bending and vertical shear loads is shown in figure $12 \mathrm{~d}$ for a crack length of 16.0 inches. The crack-growth trajectory for this case is a non-self-similar crack-growth trajectory due to the nonsymmetry of the geometry. The deformed shape for this crack length is shown in figure 14. The crack-growth trajectory for the crack located midway between two stringers in a panel subjected to internal pressure and torsion shear loads is shown in figure $12 \mathrm{e}$ for a crack length of 16.0 inches. The crack-growth trajectory for this case is a non-selfsimilar crack-growth trajectory due to the nonsymmetry of the loading condition. The deformed shape for this crack length is shown in figure 15 . These results indicate that the loading condition and crack location affect the crack-growth trajectories.

The effects of varying failsafe-strap thickness on the stress intensity factors $K_{1}$ and $K_{11}$ for a panel with a longitudinal crack and subjected to internal pressure and bending or a torsion load are shown in figures 16a and $16 \mathrm{~b}$, respectively. The results in the figures are for failsafe-strap thicknesses of $0.018,0.036$ and 0.054 inches. The results for internal pressure and the bending load are represented by the solid curves, and the results for the internal pressure and the torsion load are represented by the dashed curves. The length of the crack varies from 6.0 to 18.5 inches. The results presented in figure $16 a$ indicate that $K_{1}$ increases as the failsafe-strap thickness decreases. The rate of increase in $K_{1}$ as the crack length increases decreases as the crack approaches the frames and the load in the skin is redistributed to the frames. The results presented in figure $16 \mathrm{~b}$ indicate that $K_{n}$ is not significantly affected by the failsafe-strap thickness. The crack-growth trajectories for the 0.018-and 0.054-inch-thick failsafe straps are similar to the results shown in figure $12 \mathrm{e}$ for the panel with the 0.036-inch-thick failsafe strap. These results indicate that the crack-growth trajectory does not change as the thickness of the failsafe strap changes, but the stress-intensity factors increase as the failsafe-strap thickness increases. As a result, the higher values of the stress-intensity factors will cause the structure with thinner failsafe straps to fail at a lower load level than a structure with a thicker failsafe strap.

\section{Concluding Remarks}

The results of an analytical study of the effects of long cracks on the nonlinear response of stiffened fuselage shells subjected to combined internal pressure and mechanical loads are presented. The results indicate that nonlinear stiffened-shell analyses provide accurate predictions of the global and local responses of stiffened shells that have long cracks and are subjected to combined loads. Large local stress and out-of-plane deflection gradients that exist near cracks in stiffened shells are predicted accurately with a nonlinear stiffenedshell analysis. The nonlinear analysis accounts for the coupling that occurs between the in-plane stress resultants and the out-of-plane displacements in the neighborhood of the crack.

The results of the nonlinear analyses show that the response of a damaged stiffened shell subjected to combined internal pressure and mechanical loads is affected by both the internal pressure and the mechanical loads. The effects of a longitudinal crack on the shell response depends on the applied loading condition and the location of the crack. Bending and vertical shear loads that cause compressive axial stress resultants can couple with the out-of-plane displacements in the region of a longitudinal crack to amplify the magnitudes of the local stresses and displacements in the crack region. These compressive axial stress resultants can close a circumferential crack and reduce the crack-opening stress-intensity factor associated with the crack. Torsion loads can significantly affect the local response of a shell with a circumferential crack by causing the edges of the crack to shear relative to one another and by increasing the crack-shearing stress-intensity factor associated with the crack. Different combinations of internal pressure, bending, vertical shear and torsion loads can cause high values of both the crack-opening and the crack-shearing stress-intensity factors. The 
residual strength of a stiffened fuselage shell with a long crack can be determined from these stress-intensity factors.

As a crack grows in a stiffened shell, the internal loads are redistributed from the fusclage skin to other structural elements, such as frames, stringers and failsafe straps, and this intemal load redistribution affects the magnitudes of the stress-intensity factors associated with a crack. Varying the thickness of the failsafe straps or stringers can affect the magnitudes of the stress-intensity factors, which will affect residual strength. The crack-growth trajectory can be influenced by the crack location and by the loading condition. Nonsymmetric loading conditions or geometries can cause non-self-similar crack-growth trajectories.

\section{References}

1. Riks, E., "Bulging Cracks in Pressurized Fuselages: A Numerical Study," NLR MP 87058 U, NLR National Aerospace Laboratory, The Netherlands, September 1987.

2. Ansell, H., "Bulging of Cracked Pressurized Aircraft Structure," PhD Thesis No. 138, Linkoping Institute of Technology, Department of Mechanical Engincering, Report No. LIUTEK-LIC-1988:11, S-581, Linkoping, Sweden, April 1988.

3. Rankin, C. C., Brogan, F. A., and Riks, E., "Some Computational Tools for the Analysis of Through Cracks in Stiffened Fuselage Shells," Computational Mechanics, Springer International, Vol. 13, No. 3, December 1993, pp. 143-156.
4. Knops, H. A. J., "Numerical Simulation of Crack Growth in Pressurized Fuselages," PhD Dissertation, TU Delft, Faculty of Aerospace Engineering, Delft, The Netherlands, 1994.

5. Starnes, James H., Jr., Britt, Vicki O., and Rankin, Charles C., "Nonlinear Response of Damaged Stiffened Shells Subjected to Combined Internal Pressure and Mechanical Loads," AIAA Paper 95-1462, April 1995.

6. Brogan, F. A., Rankin, C. C., and Cabiness, H. D., "STAGS User Manual," Lockheed Palo Alto Research Laboratory, Report LMSC P032594, 1994.

7. Riks, E., "Some Computational Aspects of the Stability Analysis of Nonlinear Structures," Computational Methods in Applied Mechanics and Engineering, Vol. 47, pp. 219-259, 1984.

8. Riks, E., "Progress in Collapse Analysis," Journal of Pressure Vessel Technology, Vol. 109,1987 , pp. $27-41$.

9. Riks, E., Brogan, F. A., Rankin, C. C., "Bulging of Cracks in Pressurized Fuselages: A Procedure for Computation," in Analytical and Computational Models of Shells, Noor, A. K., Bclytschko, T., and Simo, J. C., Editors, The American Society of Mechanical Engineers, ASME-CED Vol. 3, 1989.

10. Potyondy, D. O., "A Software Framework for Simulating Curvilinear Crack Growth in Pressurized Thin Shells," PhD Dissertation, Cornell University, Ithaca, NY, 1993. 


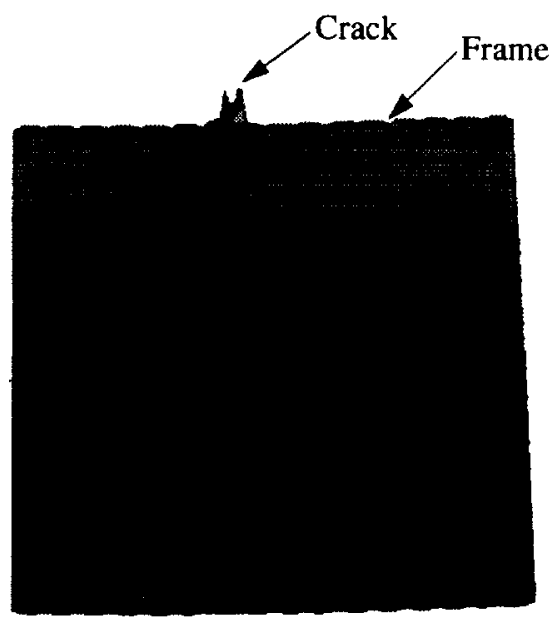

(a) Axial stress resultant distribution.

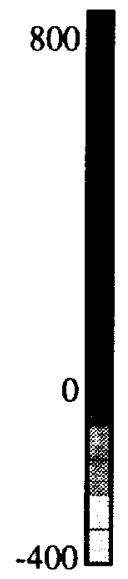

lb/in

Fig. 1 Stress resultant distributions in a stiffened fuselage shell with a 10 -inch-long longitudinal crack in a crown panel and subjected to internal pressure, torsion and bending loads.

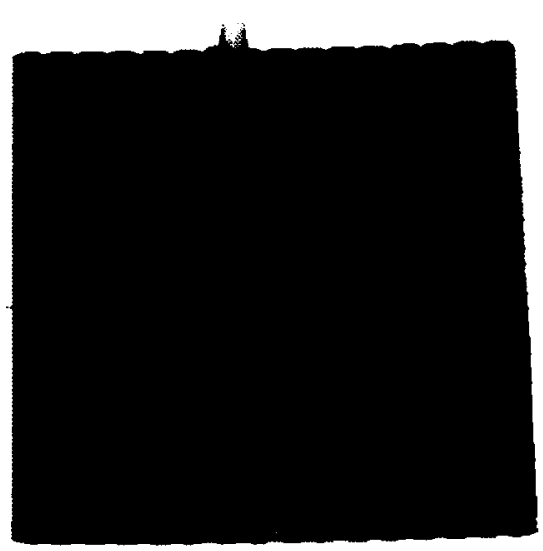

(b) Hoop stress resultant distribution.

Fig. 1 Continued.

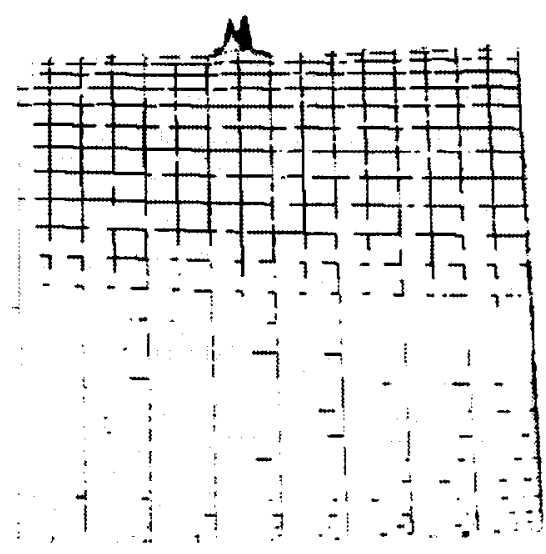

(c) Shear stress resultant distribution.

Fig. 1 Concluded.

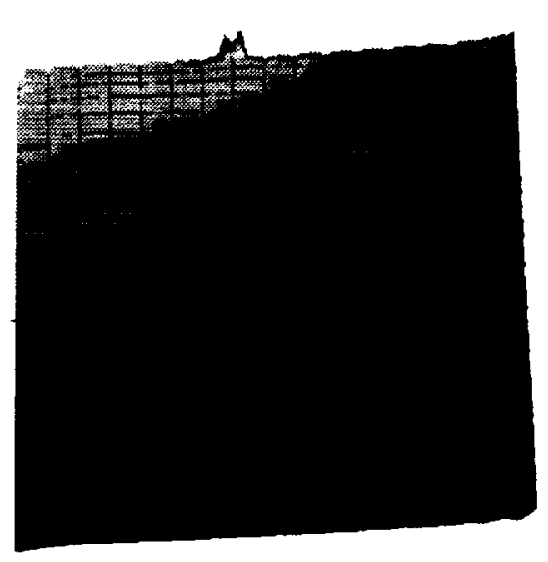

(a) Axial stress resultant distribution.

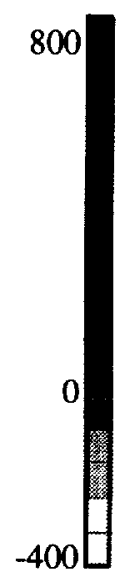

$\mathrm{lb} / \mathrm{in}$

Fig. 2 Stress resultant distributions in a stiffened fuselage shell with a 10 -inch-long longitudinal crack in a crown panel and subjected to internal pressure, vertical shear, torsion and bending loads.

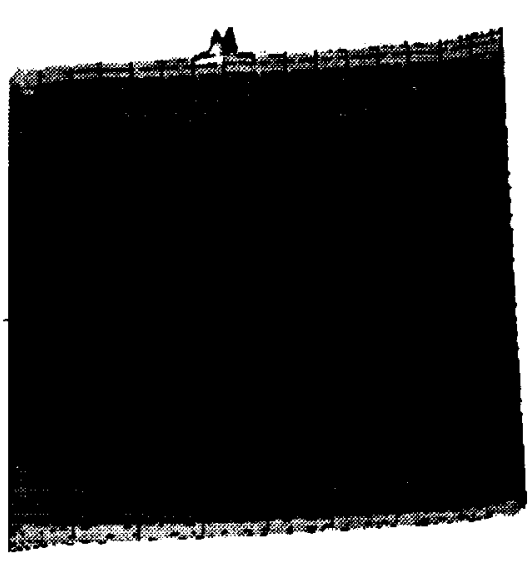

(b) Shear stress resultant distribution.

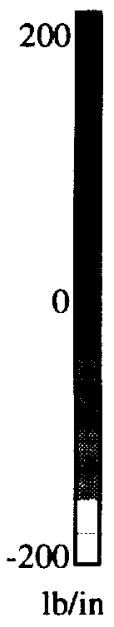

Fig. 2 Concluded.

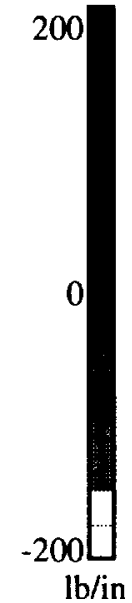




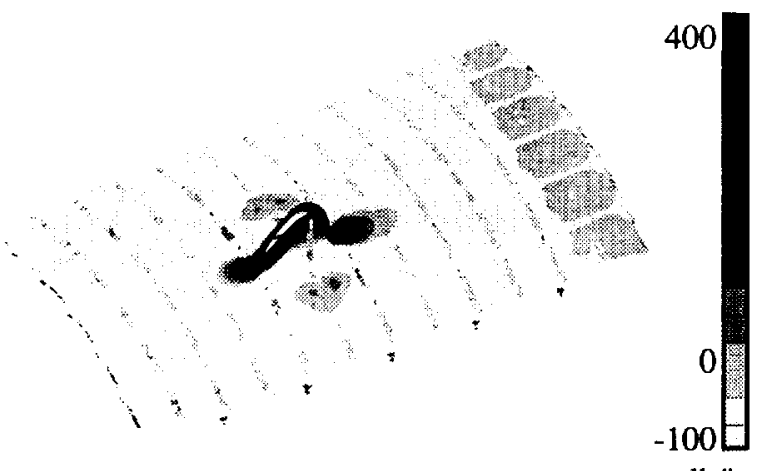

(a) Axial stress resultant distribution.

Fig. 3 Stress resultant distributions in a six-bay by six-bay stiffened fuselage crown panel with an 18.5inch-long longitudinal crack and subjected to internal pressure, vertical shear and bending loads.

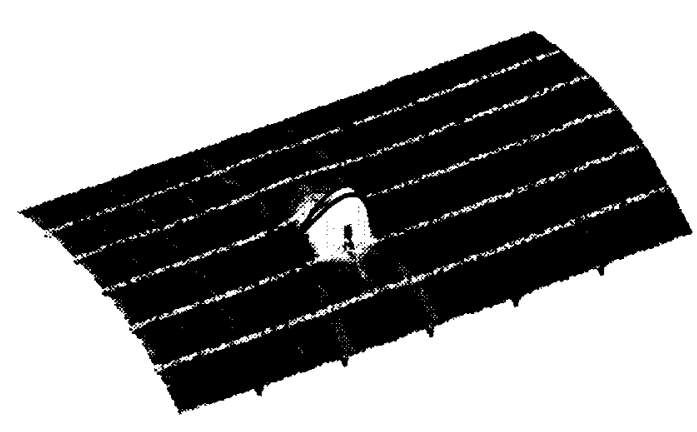

(b) Hoop stress resultant distribution.

Fig. 3 Continued.

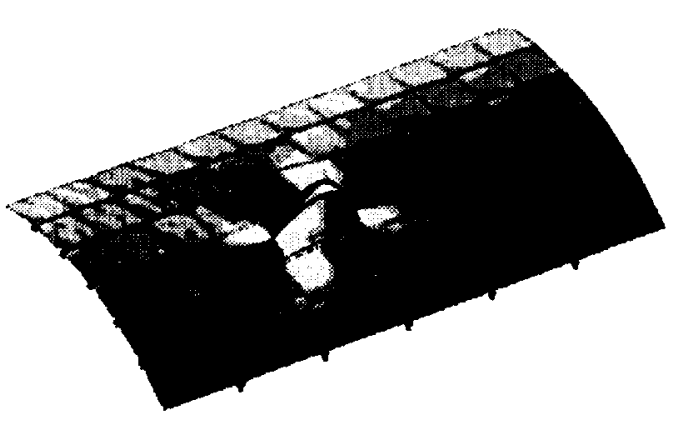

(c) Shear stress resultant distribution.

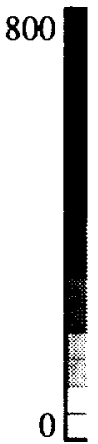

$\mathrm{lb} /$ in

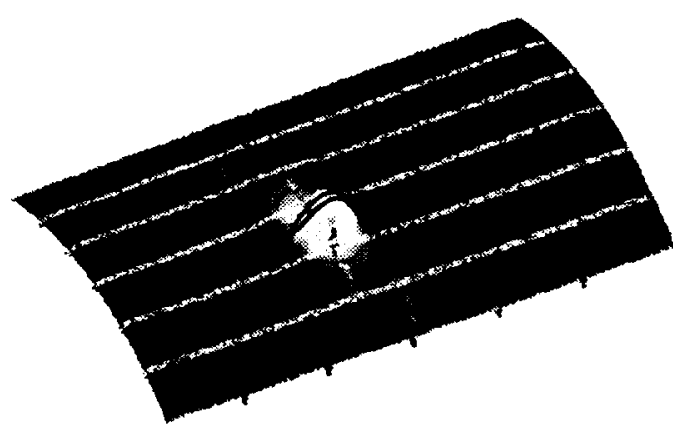

(b) Hoop stress resultant distribution.

Fig. 4 Continued.

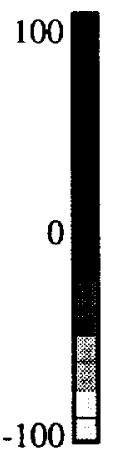

$\mathrm{lb} /$ in

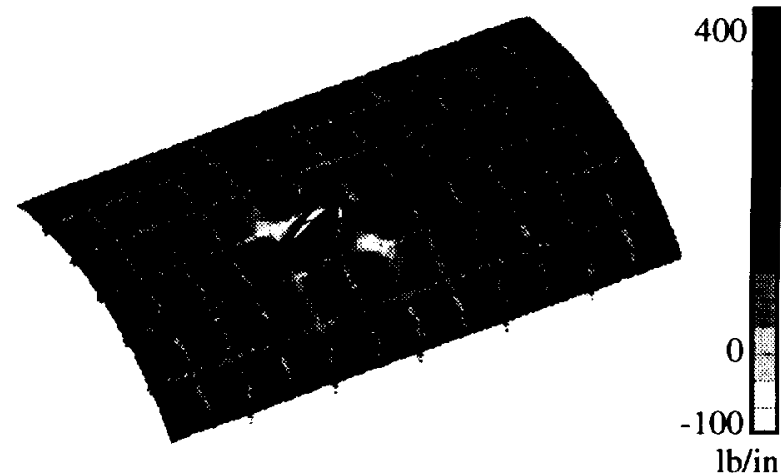

(a) Axial stress resultant distribution.

Fig. 4 Stress resultant distributions in a six-bay by six-bay stiffened fuselage crown panel with an 18.5inch-long longitudinal crack and subjected to internal pressure and torsion loads.

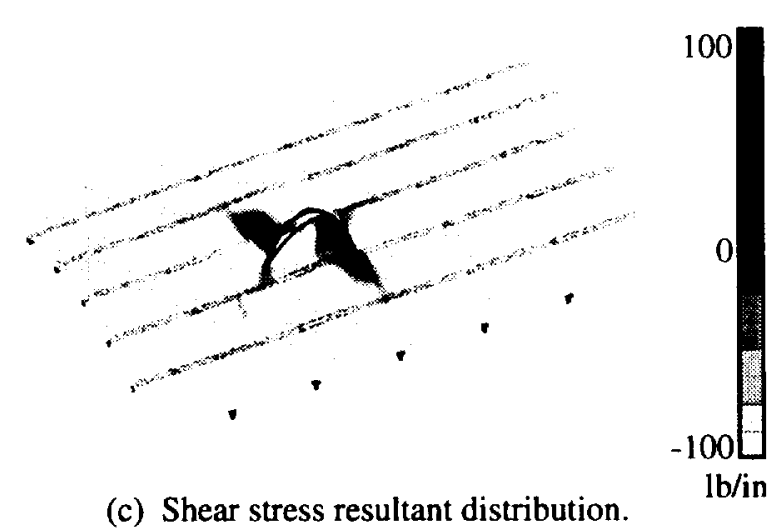

Fig. 3 Concluded.

Fig. 4 Concluded. 


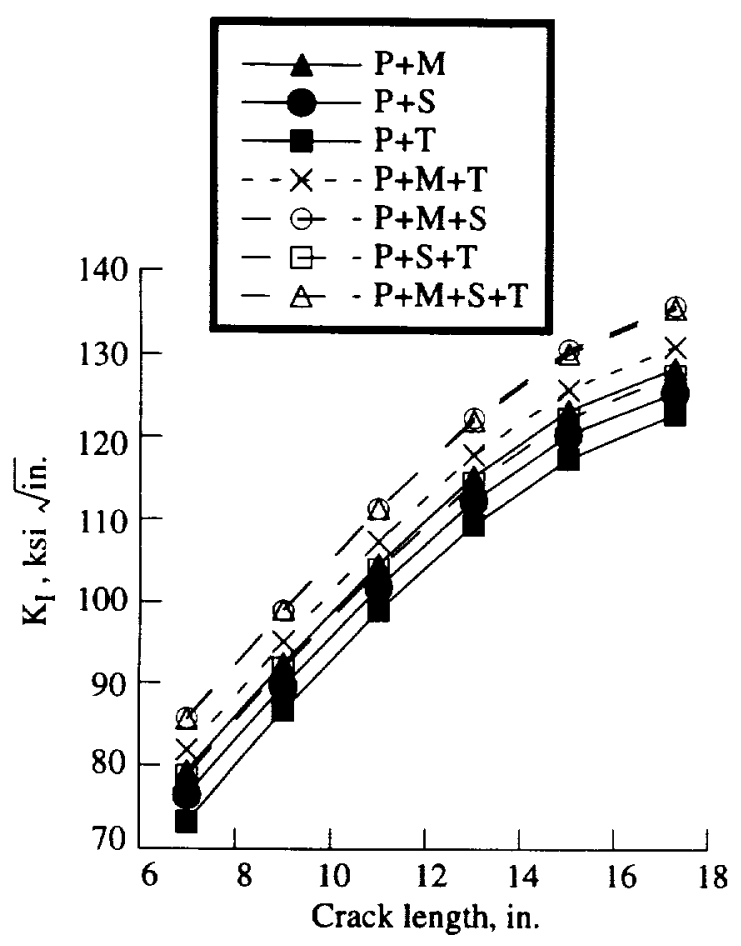

(a) $\mathrm{K}_{\mathrm{I}}$ stress-intensity factor.

Fig. 5 Stress-intensity factors for a six-bay by sixbay stiffened fuselage crown panel with an 18.5inch-long longitudinal crack subjected to internal pressure and mechanical loads.

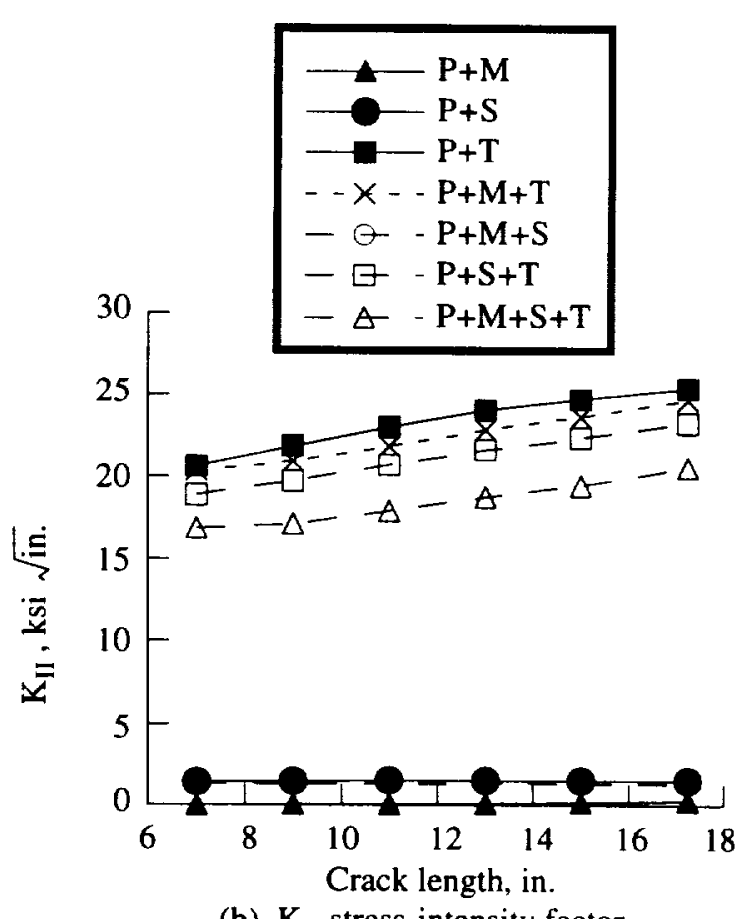

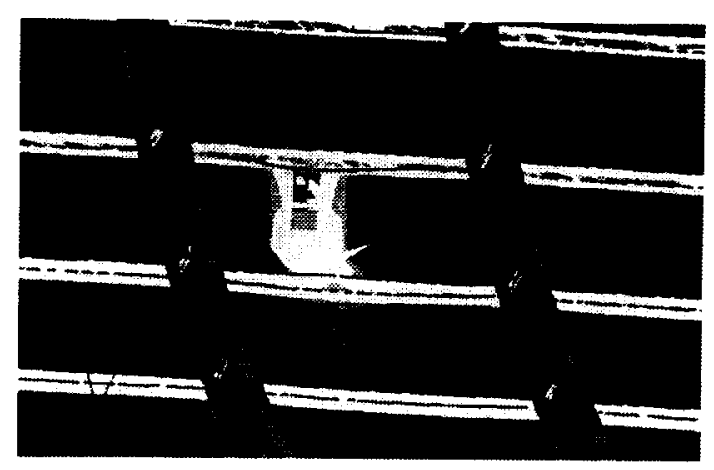

(a) 8.0-inch-long crack.

Fig. 6 Effect of crack length on the hoop stress resultant distribution and stringer distortion in a sixbay by six-bay stiffened fuselage crown panel with a longitudinal crack and subjected to internal pressure, vertical shear and bending loads.

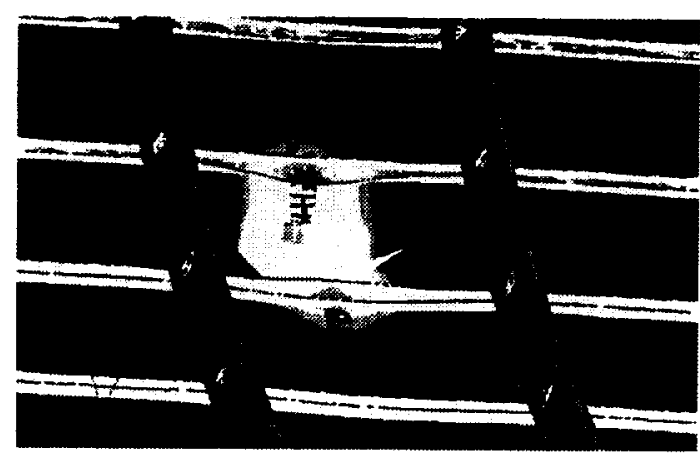

(b) 12.0-inch-long crack.

Fig. 6 Continued.

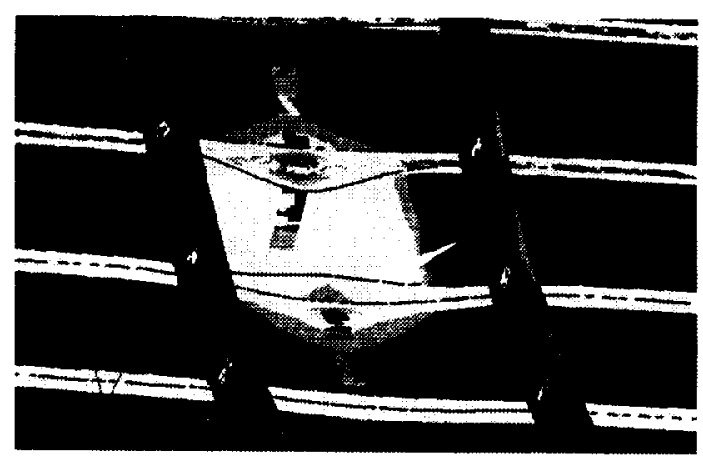

(c) 18.5-inch-long crack.

Fig. 6 Concluded.

Fig. 5 Concluded. 


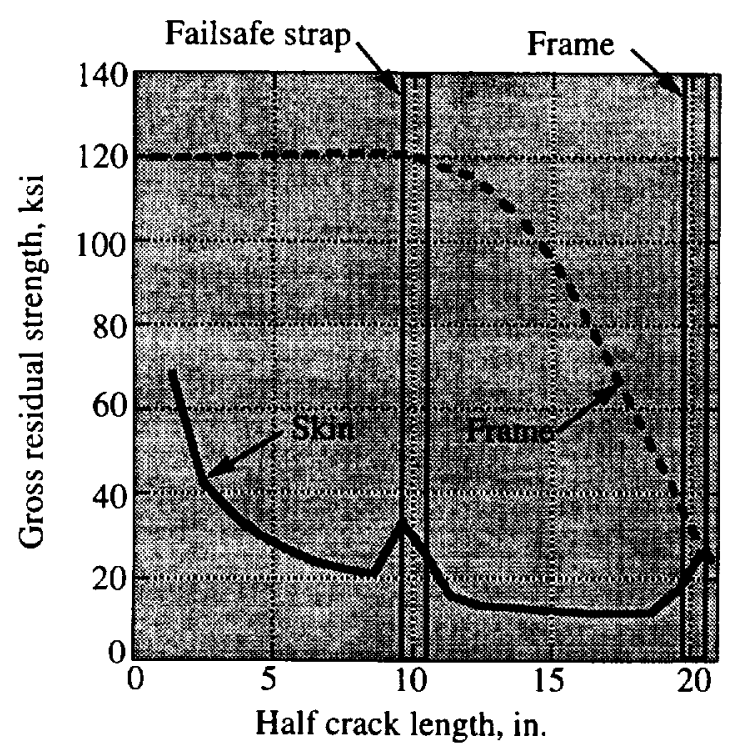

Fig. 7 Residual strength of a stiffened fuselage crown panel with a longitudinal skin crack and broken frame, and subjected to internal pressure.

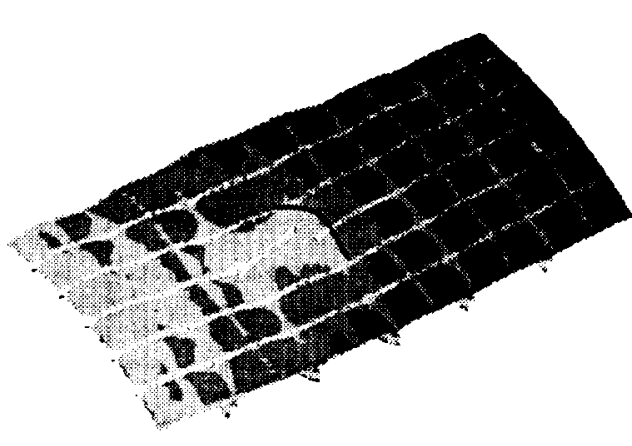

(a) Axial stress resultant distribution.

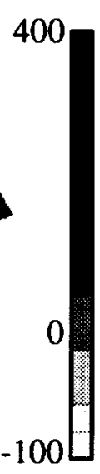

Fig. 8 Stress resultant distributions in a six-bay by six-bay stiffened fuselage crown panel with a 17.7inch-long circumferential crack and subjected to internal pressure and vertical shear loads.
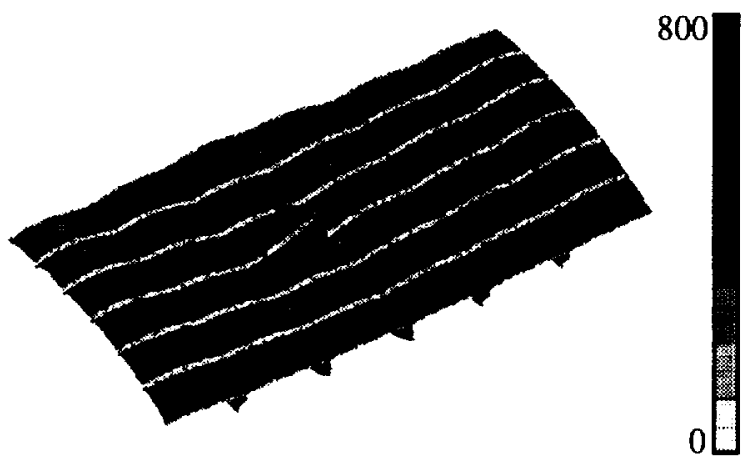

(b) Hoop stress resultant distribution.

$\mathrm{lb} /$ in

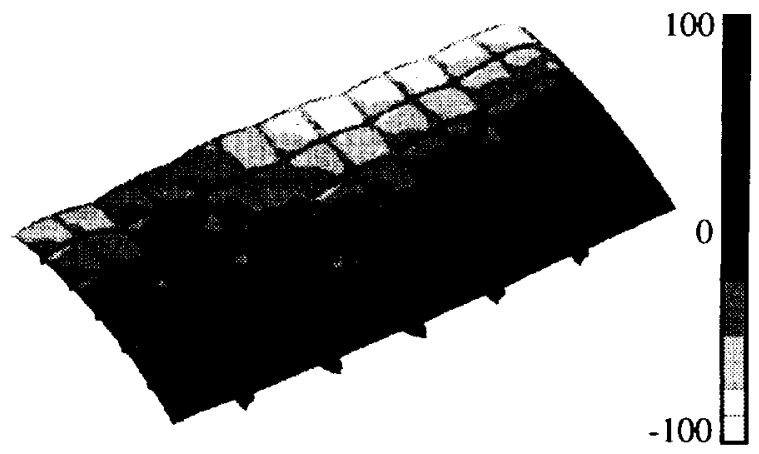

(c) Shear stress resultant distribution.

$\mathrm{lb} / \mathrm{in}$

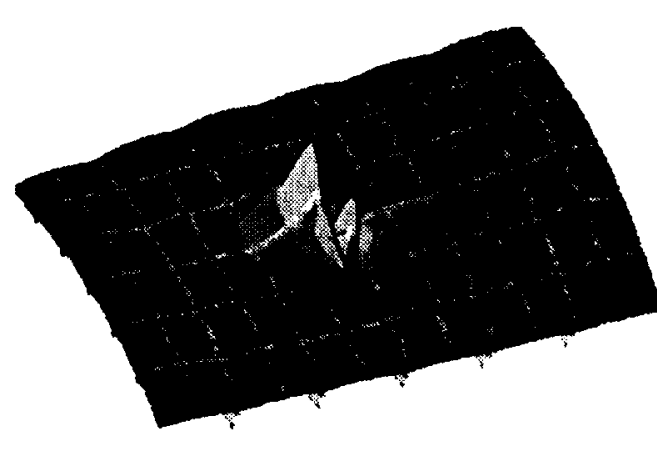

(a) Axial stress resultant distribution.

Fig. 9 Stress resultant distributions in a six-bay by six-bay stiffened fuselage crown panel with a 17.7inch-long circumferential crack and subjected to internal pressure and torsion loads.
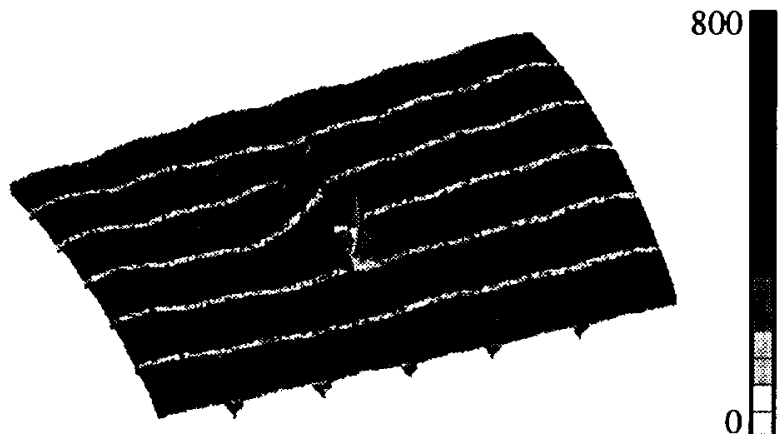

(b) Hoop stress resultant distribution.

$\mathrm{lb} /$ in

Fig. 8 Continued. 


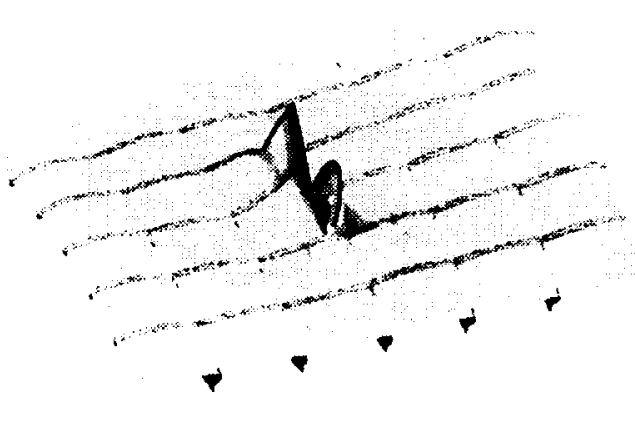

(c) Shear stress resultant distribution.

Fig. 9 Concluded.

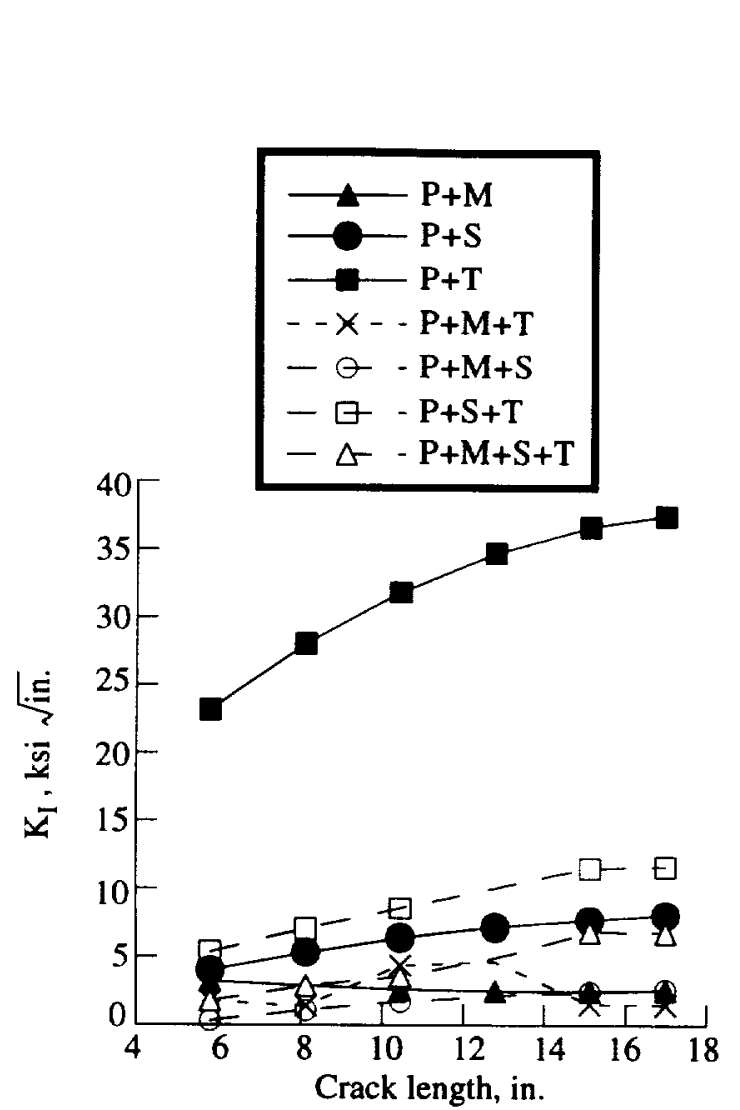

(a) $\mathrm{K}_{\mathrm{I}}$ stress-intensity factor.

Fig. 10 Stress-intensity factors for a six-bay by six-bay fuselage crown panel with an 17.7-inchlong circumferential crack and subjected to internal pressure and mechanical loads.

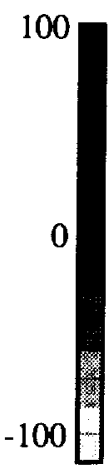

$\mathrm{lb} /$ in 


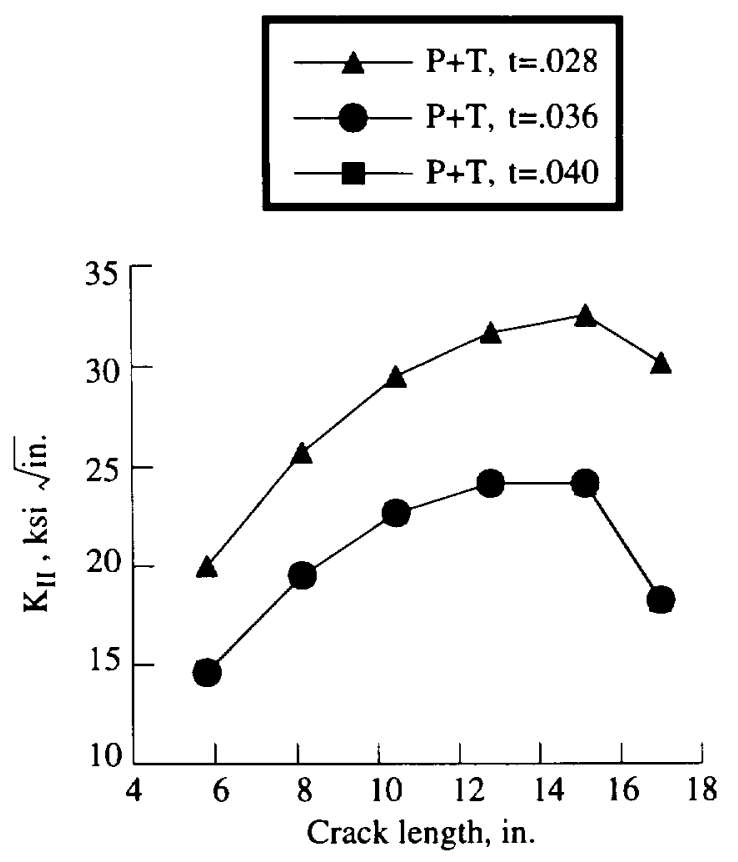

(b) $\mathrm{K}_{\mathrm{II}}$ stress-intensity factor.

Fig. 11 Concluded.

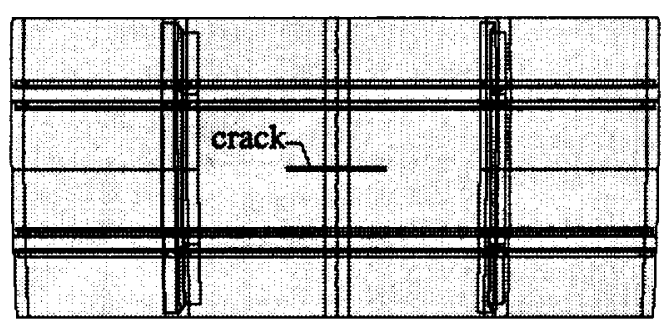

(a) 6-inch-long initial crack length for longitudinal crack located midway between two stringers.

Fig. 12 Crack growth trajectories for two-bay by three-bay stiffened fuselage crown panel with a 6.0inch-long initial crack length.

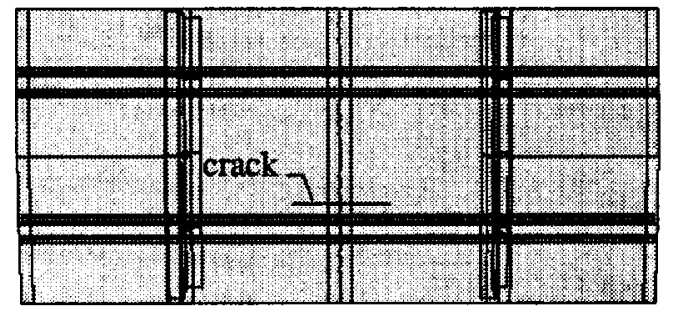

(b) 6-inch-long initial crack length for crack located 1.2 inches from a stringer.

Fig. 12 Continued.

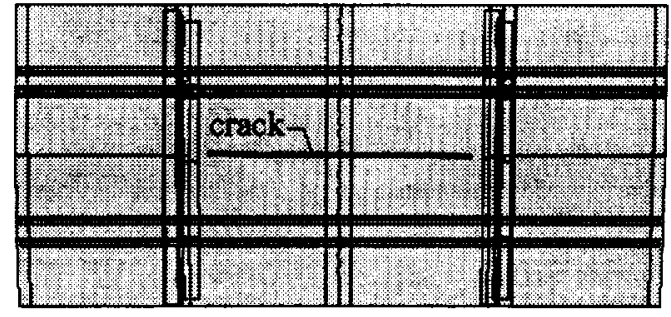

(c) 16-inch-long crack trajectory for internal pressure, bending and vertical shear loads with crack midway between two stringers.

Fig. 12 Continued.

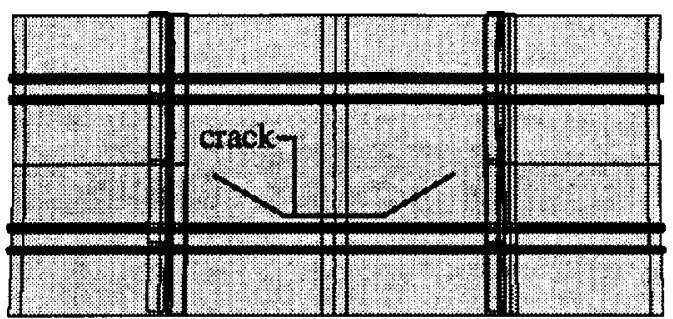

(d) 16-inch-long crack trajectory for internal pressure, bending and vertical shear loads with crack 1.2 inches from a stringer.

Fig. 12 Continued.

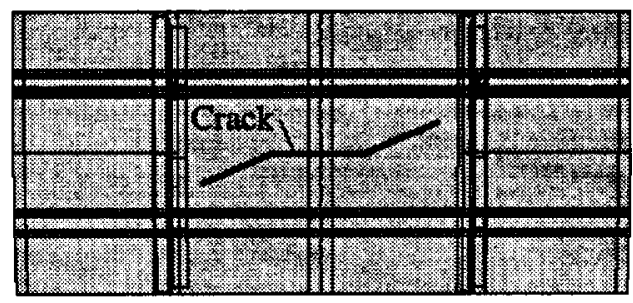

(e) 16-inch-long crack trajectory for internal pressure and torsion loads with crack initially midway between two stringers.

Fig. 12 Concluded.

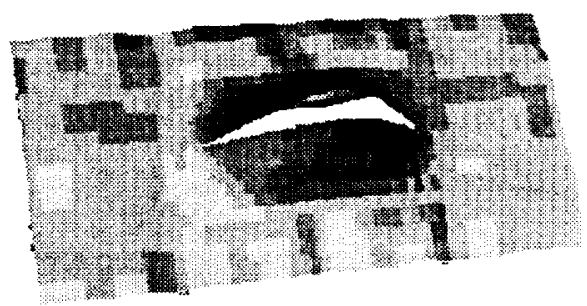

Fig. 13 Deformed shape of a two-bay by threebay stiffened fuselage crown panel with an 16.0inch-long longitudinal crack located midway between two stringers and subjected to internal pressure, moment and vertical shear loads. 


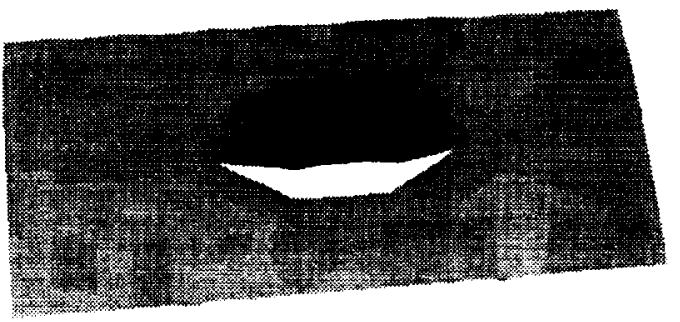

Fig. 14 Deformed shape of a two-bay by threebay stiffened fuselage crown panel with a 16.0inch-long longitudinal crack located 1.2 inches from a stringer and subjected to internal pressure, moment and vertical shear loads.

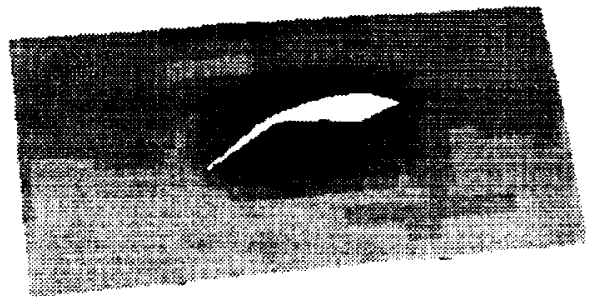

Fig. 15 Deformed shape of a two-bay by threebay stiffened fuselage crown panel with a 16.0inch-long longitudinal crack located midway between two stringers and subjected to internal pressure and torsion loads.

$$
\begin{array}{r}
\mathrm{P}+\mathrm{M}, \mathrm{t}=.018 \\
-\mathrm{P}+\mathrm{M}, \mathrm{t}=.036 \\
-\triangle-\mathrm{P}+\mathrm{M}, \mathrm{t}=.054 \\
-\Theta-\mathrm{P}+\mathrm{T}, \mathrm{t}=.018 \\
-\square-\mathrm{P}+\mathrm{T}, \mathrm{t}=.056
\end{array}
$$

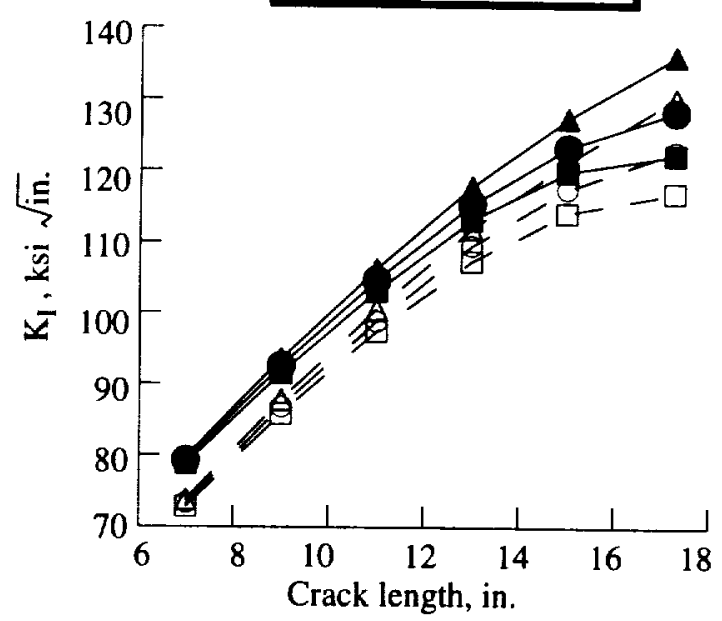

(a) $\mathrm{K}_{\mathrm{l}}$ stress-intensity factor.

Fig. 16 Effects of varying failsafe-strap thickness on the stress-intensity factors for a six-bay by sixbay stiffened fuselage crown panel with an 18.5inch-long longitudinal crack and subjected to internal pressure, bending and torsion loads.

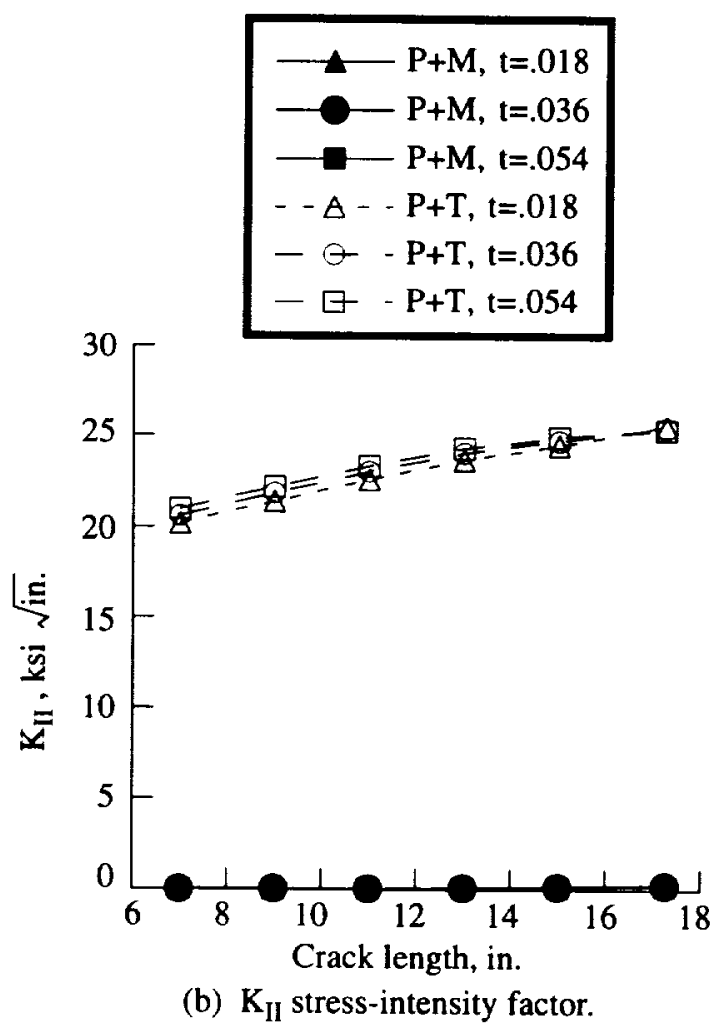

Fig. 16 Concluded. 